\title{
Aviation is not the only industry: healthcare could look wider for lessons on patient safety
}

\section{Joanne Shaw, ${ }^{1}$ Keith Calder ${ }^{2}$}

Aviation safety was back in the news earlier in 2008, following the crash landing of a Boeing 777 just inside the perimeter fence at London's Heathrow airport on 18 January. Back in 2000, the Chief Medical Officer for England, Liam Donaldson, drew heavily on the airline industry in his seminal report on patient safety "An Organisation with a Memory." Since then, aviation has become the case study of choice when translating lessons on safety from the commercial arena to healthcare. A few examples of the genre are included in the references to this article. ${ }^{1-6}$ Airline practice has much to teach us about safety culture and systems, but it may not be the best overall comparator. Making safety a top priority is the biggest challenge in healthcare. In aviation, where safety failures lead to catastrophe and death on a grand scale, prioritising safety is a nonissue. Therefore, by focusing so narrowly on the airline sector, we may be missing useful lessons from other industries.

Mining is a very old, dirty and labourintensive business, with clear parallels to healthcare. Since prehistoric times, humankind has extracted materials from the earth, layering new technologies over old, turning simple premechanised processes into complex industrialised ones, and taking on ever-greater challenges.

In the mid 1990s, Rio Tinto employed 36000 people and operated mines in 20 countries of the world. It led practice in the industry and was proud of its operational management, including safety. Then, in 1998, 10 rescuers were killed trying to save a trapped miner at the Lassing talc mine in Austria. ${ }^{7}$ This devastating accident stunned Rio Tinto and triggered a period of intense internal review. Senior management concluded that although Rio Tinto's safety standards were indeed good in relation to its own industry, mining as a whole lagged behind other sectors such as chemicals. They

${ }^{1}$ NHS Direct, London, UK; ${ }^{2}$ Rio Tinto, Vancouver, British Columbia, Canada

Correspondence to: MrsJoanne Shaw, NHS Direct, Riverside House, 2a Southwark Bridge Road, London SE1 9HA, UK; joanne.shaw@healthstrategy.org realised that improving safety would require deep changes in the company's priorities and way in which it had been managed.

The key elements of the changes were: rigorous analysis; focus on a few priority areas; application and enforcement of specific standards; company-wide training; and, above all, clear and visible leadership at the highest levels.

First, records of every "near hit" (Rio Tinto-speak for what are more commonly known as "near misses") and death within the company over the previous 10 years anywhere in the world were recalled and reviewed. Common threads were identified. For each of the top danger areas-vehicles and driving; working at heights; and electrical-common causes of accidents were investigated and solutions identified. The solutions were turned into specific standards, such as "no working above $1.2 \mathrm{~m}$ without a restraint," which were then applied across the entire company, backed up by universal training programmes. Thousands of people were trained to go out and talk about safety in the workplace.

This top-down approach was deeply countercultural for Rio Tinto. It cut across the autonomy with which local management had traditionally run their mining operations. Unlike in the NHS, Rio Tinto managers were used to a great deal of freedom. The company set operating and financial targets, but how these targets were achieved was up to local management. Unsurprisingly, the centrally driven focus on safety did not go unchallenged. People asked whether the purpose of the company was producing ore, or profit or safety. They wondered, for example, why they now had to begin every meeting, however large or small, with a $5 \mathrm{~min}$ "Safety Share" in which anyone who had anything to contribute relating to safety or health was invited to share their observations so that everyone could learn together.

The answer was that units with good operating and profitability records also had good safety records. Safety became the barometer of performance at every level of the company. The most senior leaders had a very simple message to the business units: "If you can't manage safety, you can't manage in Rio Tinto." The Safety Share was only one of many methods used to communicate the importance of safety throughout the business. Top managers visiting sites always asked workers about safety. The first thing every business unit manager was asked by their boss became "How are you doing on safety?" Each time that question was asked, it sent a message. As a result, safety moved to the top of the agenda and stayed there.

Nearly 10 years after the Lassing incident, the company's All Injury Frequency Rate (AIFR) has improved $78 \%$. AIFR is defined as the number of all injuries for an exposure of $200000 \mathrm{~h}$ worked. All injuries are the sum of medical treatment cases and lost time injuries. Medical treatment cases are those that result in loss of consciousness or medical treatment beyond first aid. Lost time injuries result in at least one shift away from work or in restricted duty (source: Rio Tinto). People in Rio Tinto will tell you that they are on a journey. Not only is safety regarded as an ethical and moral priority, but getting safety right is recognised as good for business. Every meeting still begins with a Safety Share. Senior leaders' commitment to safety as a paramount objective remains visible at all levels, and the company's safety systems continue to grow and evolve. The uncomfortable conclusion is that until senior NHS leaders genuinely make safety their top priority, not much is likely to change.

Competing interests: None.

Oual Saf Health Care 2008;17:314.

doi:10.1136/qshc.2008.028340

\section{REFERENCES}

1. Kosnik LK, Brown J, Maund T. Patient safety: learning from the aviation industry. Nurs Manage 2007;38:2530 [quiz 31].

2. Doucette JN. View from the cockpit: what the airline industry can teach us about patient safety. Nursing 2006;36:50-3.

3. Patient Safety Alert. Hospital adopts aviation-based strategies to improve safety. Hosp Peer Rev 2007;32(Suppl):1-2S.

4. Lyndon A. Communication and teamwork in patient care: how much can we learn from aviation? J Obstet Gynecol Neonatal Nurs 2006;35:538-46.

5. Singh H, Petersen LA, Thomas EJ. Understanding diagnostic errors in medicine: a lesson from aviation. Qual Saf Health Care 2006;15:159-64.

6. Hart CA. Aviation industry provides roadmap to improve patient safety. Biomed Instrum Technol 2004;38:466-9.

7. Anon. Report by the International Committee of Experts on the Lassing mine accident. Commissioned by: Dr H. Farnleitner Federal Minister for Economic Affairs. ec.europa.eu/employment_social/ health_safety/docs/lassing_report_en.pdf laccessed 25 Jul 2008). 